\title{
Síndroma de Down, sexualidade e conflitos éticos: um relato de caso
}

Ricardo Veríssimo,* Madalena Vieira da Costa*

\section{RESUMO}

Introdução: A síndroma de Down (SD) é a causa genética mais comum de atraso de desenvolvimento intelectual (ADI). Apesar de o desejo sexual estar presente e de forma independente do défice cognitivo, grande parte das famílias assume um papel sobreprotetor, infantilizando estes indivíduos e tratando-os como assexuais. Tal origina lacunas na sua educação sexual (ES), aumentando a vulnerabilidade ao abuso e a comportamentos de risco. Este caso pretende reforçar a importância da ES nos indivíduos com $\mathrm{ADI}$ e alertar para questões éticas que podem surgir neste contexto.

Descrição do caso: Jovem de 22 anos, género feminino, com SD, sem outros antecedentes de relevo. Veio sozinha à consulta de planeamento familiar, por ter começado a namorar. Referiu já ter iniciado atividade sexual, embora não com o atual namorado. Nega conhecimentos sobre métodos contracetivos, referindo que nos contactos sexuais que teve, quando foi utilizada contraceção, foi por iniciativa do parceiro. Afirmou que as suas relações foram consentidas, embora numa ocasião se tenha sentido mal tratada. Neste contexto foram-lhe apresentados os diversos métodos contracetivos, tendo mostrado interesse no implante subcutâneo (IS). Foi ainda abordada a importância da prevenção das infeções de transmissão sexual (ITS), o preservativo e sua correta utilização (dado que desconhecia por completo o método) e realizada colheita para citologia cervicovaginal. Dada a dificuldade de averiguar a capacidade da jovem de assinar o consentimento informado (Cl) com a abrangência que o ato encerra, e dado a própria não saber como proceder nesta situação, foi contactada a sua mãe. Esta última afirmou que deveria ser a filha a fazê-lo, mostrando-se disponível para colaborar no processo de decisão informada. Neste momento foi decidido manter segredo em relação à vida sexual da jovem. Requisitado teste imunológico de gravidez, que foi negativo, procedeu-se então à colocação do IS, reforçando novamente a importância da utilização do preservativo. Após três meses volta à consulta para reavaliação e nova abordagem da temática da sexualidade.

Comentário: Este caso confrontou a equipa de saúde com duas questões éticas delicadas. Até que ponto o ADI torna a jovem incapaz de dar o seu Cl? Poderia o segredo médico ser escusado, no caso de ter de ser a sua mãe a assinar o $\mathrm{Cl}$, como forma de fazê-la perceber a necessidade de contraceção? Além disso, torna-se necessário capacitar pais e profissionais para a promoção da saúde sexual dos indivíduos com ADI, nomeadamente com SD. O médico de família, pelas suas características e pela posição que ocupa no sistema de saúde, tem um papel fundamental.

Palavras-chave: Síndroma de Down; Atraso do desenvolvimento intelectual; Sexualidade; Ética; Médico de família.

\section{INTRODUÇÃO}

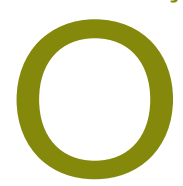

atraso de desenvolvimento intelectual (ADI) ou défice intelectual é definido na $5^{\mathrm{a}}$ edição do Manual de Diagnóstico e Estatístico de Doenças Mentais (DSM-V) como uma doença, com início no período de desenvolvimento, que inclui défices tanto intelectuais quanto no funcionamento adaptativo. ${ }^{1}$

*Médicos Internos de Medicina Geral e Familiar. USF Jardim dos Plátanos, ACeS Lisboa Ocidental e Oeiras
Ao contrário do que acontece na edição anterior, a gravidade desta entidade é estabelecida com base no funcionamento adaptativo e não na pontuação obtida num teste de inteligência como, por exemplo, o Quociente de Inteligência (QI). A justificação para esta alteração prende-se com o facto de o funcionamento adaptativo ser o fator determinante do nível de apoios necessários ao indivíduo. Assim, torna-se fundamental a avaliação do indivíduo nos diversos domínios: concetual, social e prático. ${ }^{1}$ 
O ADI, com uma prevalência de aproximadamente $3 \%$ no mundo ocidental, tem inúmeras etiologias que podem agrupar-se em genéticas e ambientais. A síndroma de Down (SD) é a causa genética mais comum.-3

Nos indivíduos com SD, o desenvolvimento intelectual pode variar entre o próximo do normal e o défice grave.-5 Independentemente disto, o desejo sexual está presente e a saúde sexual é para estes indivíduos, como para todos os outros, um direito básico. No entanto, temendo as consequências duma gravidez com risco de reincidência da síndroma e antecipando eventuais obstáculos na concretização do poder parental, a maior parte das famílias tende a assumir um papel sobreprotetor, tratando estes indivíduos num padrão infantil de comportamento e como assexuais. ${ }^{6-7}$ Este facto origina lacunas na sua educação sexual (ES), o que aumenta a sua vulnerabilidade ao abuso e a comportamentos de risco. ${ }^{4,8}$ Esta problemática ganha particular relevo numa época em que se assiste a uma maior inclusão destes indivíduos em diversos grupos sociais. ${ }^{6}$

O presente relato de caso pretende consciencializar os profissionais de saúde que diariamente contactam com adolescentes e jovens com ADI das mais diversas etiologias para a importância de os educar e orientar adequadamente no âmbito da sexualidade. Além disso, pretende debater questões éticas delicadas, e de resposta não imediata, que podem surgir neste contexto.

\section{DESCRIÇÃO DO CASO}

Identificação

Fátima (nome fictício) é uma jovem de 22 anos de idade, caucasiana. É natural de Lisboa. Tem o $9^{\circ}$ ano de escolaridade realizado em ensino integrado e trabalha em part-time. Pratica desporto regularmente e integra um grupo de teatro.

É solteira e pertence a um agregado familiar constituído pelos seus pais e irmãos. Trata-se, assim, duma família nuclear na fase $\mathrm{V}$ do Ciclo de Vida Familiar de $\mathrm{Du}$ vall.

\section{Antecedentes pessoais}

Apresenta uma SD por ter herdado uma translocação robertsoniana desequilibrada entre os cromossomas 14 e 21 da sua mãe. Além disso, sofre hipotiroidismo congénito, estando medicada com levotiroxina. Durante a infância foi submetida a amigdalectomia e ade- noidectomia. Não tem outros antecedentes patológicos de relevo.

O genograma familiar e a psicofigura de Mitchell encontram-se representados na Figura 1. O círculo familiar de Thrower encontra-se representado na Figura 2. Não há história na sua família de outras doenças de transmissão hereditária, além da SD.

\section{História da doença atual}

\section{Consulta de saúde de adultos - 29/06/2015}

Fátima veio pela primeira vez à Unidade de Saúde Familiar (USF) a uma consulta de saúde de adultos, acompanhada pela mãe, para iniciar vigilância. Até então foi seguida por pediatra que, dada a sua idade, sugeriu a transição.

Referiu praticar desporto e fazer teatro e que tinha começado a namorar recentemente com um rapaz. Não fazia outra medicação habitual além da levotiroxina. Negou consumo de álcool, tabaco ou drogas. Realizou-se um exame objetivo sumário (avaliação do peso e altura, IMC, tensão arterial, frequência cardíaca e aus-

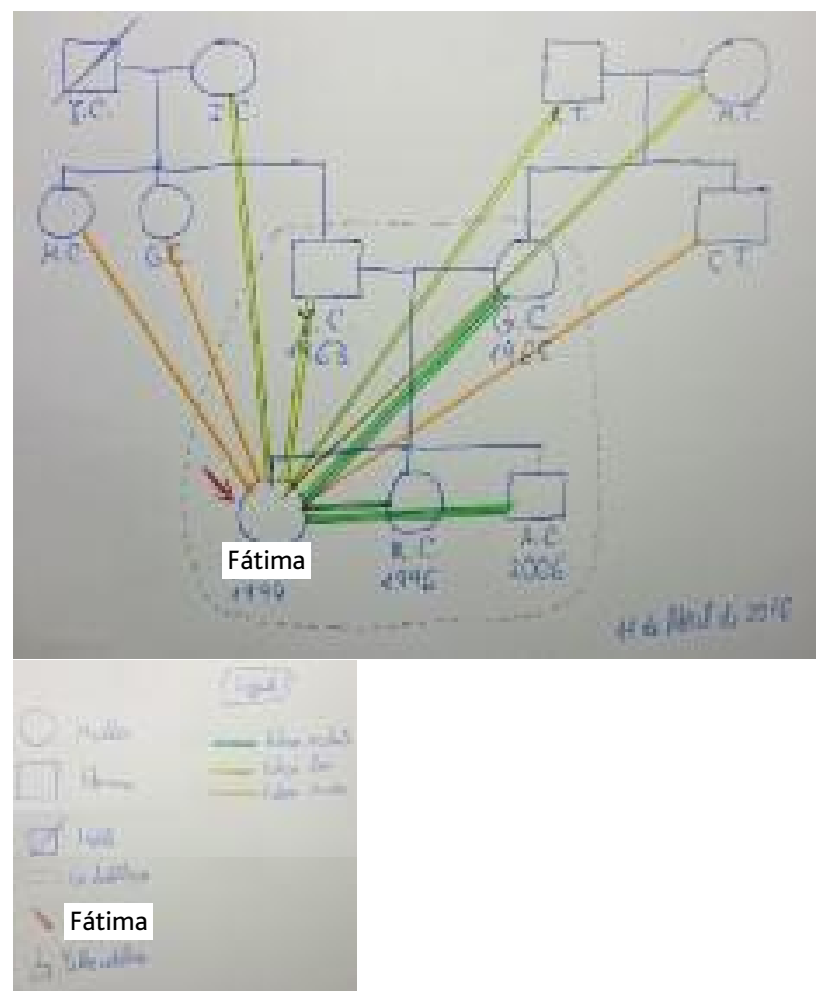

Figura 1. Genograma e psicofigura de Mitchell (data: 29.06.2015). 


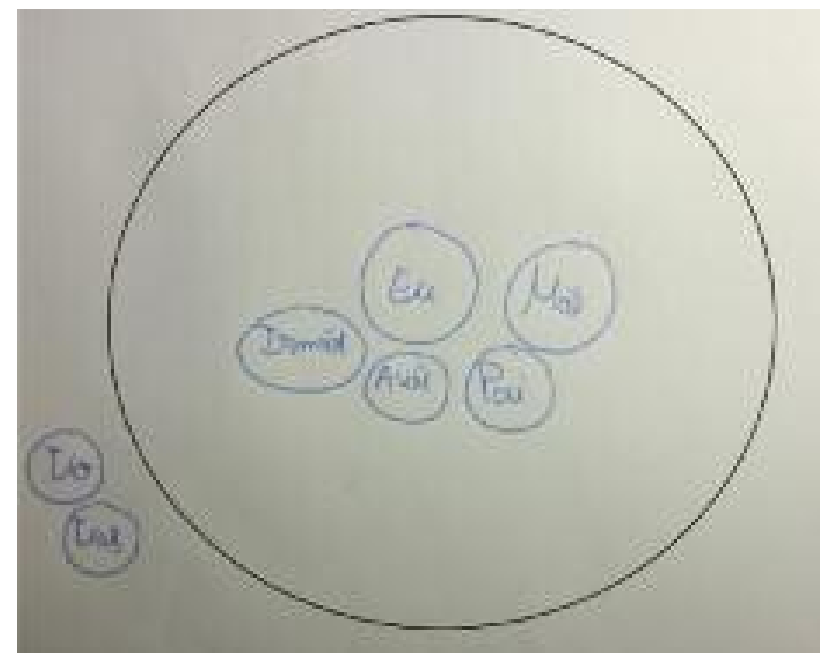

\begin{tabular}{l|c}
$\begin{array}{l}\text { Está contente com a representação que faz } \\
\text { da sua família? }\end{array}$ & Sim \\
\hline Se não, como gostaria que fosse? & ------- \\
\hline Se necessitasse de ajuda a quem pediria? & À mãe
\end{tabular}

Figura 2. Círculo familiar de Thrower (data: 29.06.2015).

cultação cardiopulmonar), que não revelou alterações clinicamente importantes. Trazia ainda um estudo analítico (hemograma, função renal, marcadores de lesão hepática, perfil lipídico e função tiroideia) recente, também sem alterações.

Dado tratar-se da primeira consulta e Fátima se encontrar no início da sua vida adulta foi decidido aplicar-se instrumentos de avaliação familiar, de entre os quais o genograma, a psicofigura de Mitchell e o círculo de Thrower.

Foi explicada a importância de manter hábitos alimentares saudáveis e feito reforço positivo acerca da prática de desporto. Por questões práticas, como a falta de tempo no momento e a indisponibilidade do espaço próprio e apoio de enfermagem, e dada a necessidade de abordar a temática da sexualidade, foi decidido agendar consulta de planeamento familiar para 29/07/2015.

\section{Consulta de planeamento familiar - 29/07/2015}

Fátima veio sozinha à consulta.

Desconhecia a idade da menarca e o padrão dos seus ciclos menstruais. Nunca tinha utilizado métodos con- tracetivos e também nunca tinha estado grávida. No entanto, já tinha iniciado atividade sexual, não se recordando da idade de início. Tinha tido múltiplos parceiros e todas estas relações sexuais tinham acontecido de acordo com a sua vontade. Recordava-se de se ter sentido mal tratada numa delas. Revelou que a mãe desconhecia a sua vida sexual ativa e não queria que viesse a saber. Não tinha tido ainda relações sexuais com o atual namorado. Partilhou também o desejo de futuramente casar e ter filhos.

Desconhecia a existência de métodos contracetivos, pelo que foi explicada a sua necessidade, importância e riscos de não utilização e apresentados vários métodos, nomeadamente o preservativo, como o único que previne infeções de transmissão sexual (ITS). De entre os métodos apresentados, a utente mostrou maior interesse no implante subcutâneo (IS) após reconhecer dificuldades no compromisso diário que a contraceção oral iria exigir e em perceber as vantagens e mecanismo de ação de outros métodos, como os sistemas intrauterinos.

Foi feito exame ginecológico, que não revelou alterações, e colheita para citologia cervicovaginal.

Agendou-se consulta para dois dias depois, para colocação do IS e, por esse motivo, requisitou-se teste imunológico de gravidez.

No final desta consulta, e face à necessidade de obter consentimento para a colocação do implante, levantaram-se duas questões de natureza ética:

1. Seria Fátima capaz de dar o seu consentimento informado (CI) para este procedimento, atendendo ao facto de apresentar um ADI? Estaria a mesma legalmente interdita de tomar decisões desta natureza?

2. No caso extremo de Fátima estar interdita, como abordar com a mãe a necessidade de contraceção não lhe contando que a filha, ao contrário do que pensa, já iniciou atividade sexual?

Foram abordadas com a utente estas questões e dado ser totalmente desconhecida a existência de interdição, contactou-se telefonicamente a sua mãe, que se disponibilizou para vir à USF no dia seguinte.

\section{Contacto presencial com a mãe - 30/07/2015}

Neste contacto, a mãe informou que devia ser a filha a assinar o CI, por ter decidido, em conjunto com o seu marido, "não lhe retirar quaisquer poderes legais". Mos- 
trou-se, no entanto, disponível para colaborar no processo de decisão informada, levando o impresso do consentimento para casa para o ler com Fátima. Nesse impresso encontram-se descritas as vantagens e desvantagens do método em causa, já enumeradas em consulta. Foi mantido segredo em relação aos pormenores da vida sexual da filha que a mãe desconhecia.

\section{Consulta de planeamento familiar - 31/07/2015}

Vem com a mãe para colocação do IS, trazendo um resultado negativo no teste imunológico de gravidez e o consentimento informado já assinado. Foi averiguada a sua compreensão das vantagens e desvantagens do método escolhido. Realizou-se o procedimento sem intercorrências e reforçou-se novamente a importância da utilização do preservativo.

Foi agendada consulta para dali a três meses para novo enfoque na sexualidade e para serem requisitadas serologias para ITS comuns que, tal como a citologia cervicovaginal, vieram a revelar-se negativas.

\section{COMENTÁRIO}

Neste episódio de cuidados, as equipas médica e de enfermagem depararam-se com duas problemáticas da maior pertinência e que aqui surgiram interrelacionadas, a da sexualidade e a da ética.

\section{Sexualidade}

São vários os estudos em matéria de sexualidade nos indivíduos com ADI e, em particular, com SD.

Num estudo transversal ${ }^{6}$ foi aplicado um questionário a 50 indivíduos com SD e idades compreendidas entre os 10 e os 20 anos. Apesar de terem apresentado dificuldades significativas na autonomia e desempenho escolar, carecendo por isso de intervenções cuidadosas para otimizar a sua interação social, concluiu-se que estes indivíduos apresentavam um desenvolvimento pubertário e exercício da sexualidade normais, estavam satisfeitos com a sua imagem corporal e tinham perspetivas futuras de trabalhar, encontrar um companheiro, casar e ter filhos. Estas conclusões coadunam-se com as de outros estudos ${ }^{9} \mathrm{e}$ com os achados descritos neste relato de caso.

Foi avaliada, também num estudo transversal com base na aplicação de questionários, a perceção de pais e profissionais de saúde sobre a sexualidade dos indi- víduos com SD. Os resultados obtidos sugeriram que, enquanto os pais viam os filhos num contexto de infantilização, havia uma maior aceitação da sua sexualidade por parte dos profissionais. ${ }^{7}$ Alguns autores alertam para o facto do risco de abuso sexual nestes indivíduos ser no mínimo $150 \%$ superior ao daqueles sem défice intelectual. Este facto está relacionado com a forma como a sociedade trata e vê (ou não vê) a sua sexualidade. ${ }^{10}$

Em relação ao casamento e à possibilidade de terem filhos, as opiniões de pais e profissionais também divergiram, de forma estatisticamente significativa. Os pais assumem nestas matérias uma postura menos permissiva. $^{7}$

Finalmente, $31,9 \%$ dos pais e $23,3 \%$ dos profissionais afirmaram não se sentirem preparados para lidar com temas de sexualidade e $80 \%$ dos pais e $84,7 \%$ dos profissionais manifestaram o desejo de receber informações. $^{7}$

As conclusões obtidas nestes estudos são idênticas ao previamente descrito na literatura.

A ES nos adolescentes com $\mathrm{AD}$ é, à semelhança de todos os outros jovens, fundamental. Contudo, estes indivíduos em particular apresentam muitas vezes competências comunicacionais limitadas, que geram dificuldades na expressão dos seus desejos e interesses. Há ainda que lembrar que os adolescentes com ADI não são todos iguais, sendo alguns mais interessados e conscientes da sua sexualidade do que outros. Uma educação apropriada deve, por isso, ir de encontro às competências e personalidade de cada um. ${ }^{11}$ Os seus objetivos devem ser, de acordo com as recomendações da Associação Americana de Pediatria, expressar os afetos de forma adequada à sua idade cronológica e desencorajar as manifestações de afeto inadequadas; obedecer aos padrões familiares e sociais de privacidade e discrição; ensinar a diferença entre comportamentos aceitáveis em público e em privado; recusar toque inapropriado, informando os pais quando este acontecer; normalizar sentimentos de prazer e afeto. $^{12}$

Se bem discutida, a ES melhora o desenvolvimento afetivo, facilitando as relações interpessoais e aumentando a autoestima e integração social. ${ }^{6}$ Tal como ilustrado neste relato de caso, é fundamental consciencializar e capacitar pais e profissionais de saúde 
para orientar estes indivíduos no âmbito da sexualidade.

\section{Ética}

Conforme já foi referido, neste episódio de cuidados levantaram-se duas questões de natureza ética relativas ao consentimento informado, livre e esclarecido e à escusa ou não do segredo médico.

Importa lembrar que o CI, em saúde, emana da atenção dada ao princípio ético da autonomia, em que se reconhece a capacidade da pessoa em assumir livremente as suas próprias decisões sobre a sua saúde e os cuidados que lhe são propostos. ${ }^{13}$

Concretamente em relação a indivíduos com défice intelectual, a norma da Direção-Geral da Saúde (DGS) $n^{\circ} 15 / 2013$ estabelece, no seu ponto $n^{\circ} 7$, que "as decisões sobre a saúde de uma pessoa que careça de capacidade para decidir obrigam, independentemente de ser tentado o seu envolvimento, à obtenção de autorização do seu representante legal, do procurador de cuidados de saúde, de uma autoridade ou de uma pessoa ou instância designada pela lei." ${ }^{13}$ Vai, deste modo, ao encontro da Convenção sobre os Direitos do Homem e a Biomedicina (Convenção de Oviedo), em cujo artigo $6^{\circ}$, ponto $\mathrm{n}^{\circ} 3$, se pode ler: "Sempre que, nos termos da lei, um maior careça, em virtude de deficiência mental, de doença ou por motivo similar, de capacidade para consentir numa intervenção, esta não poderá ser efetuada sem a autorização do seu representante, de uma autoridade ou de uma pessoa ou instância designada pela lei. A pessoa em causa deve, na medida do possível, participar no processo de autorização.”14

Fátima, apesar de ser maior, apresentava um ADI. Mas como aferir se o ADI identificado interferia de forma significativa na sua capacidade de decidir neste caso em particular? Nem a norma da DGS, aqui citada, nem a Convenção de Oviedo sugerem uma forma objetiva de o fazer. A avaliação deve, por isso, ser feita caso a caso, tendo em conta a capacidade de a pessoa entender a natureza e o efeito da decisão.

A competência de decisão dum utente é definida pela sua capacidade de receber, compreender, reter e recordar informação relevante, integrar a informação recebida e relacioná-la com a sua situação, avaliar os benefícios e riscos em termos dos seus valores pessoais, selecionar uma opção e dar razões convincentes para a escolha, comunicar a escolha a outros e perseverar com essa escolha, pelo menos até a mesma ser posta em prática. ${ }^{15}$ É possível que uma pessoa com ADI seja capaz de dar o CI em determinadas situações e não noutras de maior complexidade. ${ }^{8}$

Face a este conflito, a equipa de cuidados questionou a utente acerca da existência de algum tipo de interdição. Dado o seu desconhecimento, contactou-se telefonicamente a sua mãe (representante legal natural) para agendar um encontro. A mãe informou a equipa da inexistência de quaisquer interdições, concordando dever ser a sua filha a tomar a decisão. Entretanto, manifestou vontade em colaborar no processo, levando o impresso do consentimento para casa para o lerem em conjunto. Nele estão descritas as vantagens e desvantagens do método em causa, já previamente exploradas e explicadas na consulta a sós com Fátima.

Quando a utente regressou para realizar o procedimento já trazia o consentimento assinado. Foi, ainda assim, averiguada novamente a sua compreensão acerca do método escolhido.

A necessidade deste contacto com a mãe esteve na génese do segundo conflito ético com que a equipa foi confrontada. No caso de a interdição existir e tendo de ser a mãe, enquanto representante legal, a assinar o CI, como abordar a necessidade de contraceção para a sua filha, respeitando o segredo médico e sem lhe contar que a mesma, ao contrário do que pensa, já iniciou atividade sexual.

O Código Deontológico da Ordem dos Médicos estabelece, no seu artigo ${ }^{\circ} 88$, que se excluem do dever de segredo médico "O que for absolutamente necessário à defesa da dignidade, da honra e dos legítimos interesses do médico ou do doente, não podendo em qualquer destes casos o médico revelar mais do que o necessário, nem o podendo fazer sem prévia autorização do Presidente da Ordem." ${ }^{16}$

A confidencialidade foi totalmente respeitada neste caso. Adicionalmente foram encontradas outras formas de consciencializar a mãe para a necessidade de orientar a sua filha no âmbito da sexualidade e em matéria de contraceção. Afinal, a ES impõe-se nesta situação como para qualquer outro adolescente.

\section{CONCLUSÃO}

Em suma, este relato de caso pôs em evidência uma 
série de questões, tanto éticas quanto do âmbito da medicina sexual e saúde reprodutiva. Torna-se importante que os pais, com o apoio dos profissionais de saúde, deixem de lado a visão infantilizada dos seus adolescentes com ADI, nomeadamente SD, para que se possam colmatar lacunas na sua ES. Esta educação deve ser individualizada e com base nas competências e personalidade de cada um e revela-se fundamental para a prevenção do abuso e de comportamentos de risco nesta população, que é também ela de risco. O médico de família, pelas suas características e pela posição que ocupa no sistema de saúde, tem aqui um papel fundamental. Além disso, importa rever a legislação e as diretrizes que dizem respeito ao $\mathrm{CI}$ e à confidencialidade, de forma a torná-las mais claras, específicas e aplicáveis num ponto de vista prático. Para tal, é necessária também mais investigação.

\section{REFERÊNCIAS BIBLIOGRÁFICAS}

1. American Psychiatric Association. Diagnostic and statistical manual of mental disorders (DSM-V). 5th ed. Arlington, VA: APA; 2013. ISBN 9780890425541

2. Oliveira R, Rodrigues F, Venâncio M, Saraiva JM, Fernandes B. Avaliação e investigação etiológica do atraso do desenvolvimento psicomotor / défice intelectual [Etiologic evaluation and investigation of global development delay and intelectual disability]. Saúde Infantil. 2012;34(3): 5-10. Portuguese

3. Katz G, Lazcano-Ponce E. Intellectual disability: definition, etiological factors, classification, diagnosis, treatment and prognosis. Salud Publica Mex. 2008;50 Suppl 2:s132-41.

4. Watson SL, Richards DA, Miodrag N, Fedoroff JP. Sex and genes, part 1: sexuality and Down, Prader-Willi and Williams syndromes. Intellect Dev Disabil. 2012;50(2):155-68.

5. Van Cleve SN, Cannon S, Cohen WI. Part II: clinical practice guidelines for adolescents and young adults with Down syndrome: 12 to 21 years. J Pediatr Health Care. 2006;20(3):198-205.

6. Bononi BM, Sant'Anna MJ, de Oliveira AC, Renattini TS, Pinto CF, Passarelli ML, et al. Sexuality and persons with Down syndrome: a study from Brazil. Int J Adolesc Med Health. 2009;21(3):319-26.
7. Castelão TB, Schiavo MR, Jurberg P. Sexualidade da pessoa com síndrome de Down [Sexuality in Down syndrome individuals]. Rev Saúde Pública. 2003;37(1):32-9. Portuguese

8. Eastgate G. Sex, consent and intellectual disability. Aust Fam Physician. 2005;34(3):163-6.

9. Pueschel SM, Scola PS. Parent's perception of social and sexual functions in adolescents with Down's syndrome. J Ment Defic Res. 1988;32 (Pt 3):215-20.

10. Sobsey D. Violence and abuse in the lives of people with disabilities: the end of silent acceptance? Baltimore, MD: Paul H. Brookes; 1994. ISBN 1557661480

11. Baumer N, Davidson EJ. Supporting a happy, healthy adolescence for young people with Down syndrome and other intellectual disabilities: recommendations for clinicians. Curr Opin Pediatr. 2014;26(4):42834.

12. Committee on Children with Disabilities of the American Academy of Pediatrics. Sexual education of children and adolescents with developmental disabilities. Pediatrics. 1996;97(2):275-8.

13. Direção-Geral da Saúde. Consentimento informado, esclarecido e livre dado por escrito: norma da DGS n 015/2013, de 03/10/2013, atualizada a 04/11/2015. Lisboa: DGS; 2015.

14. Decreto $n^{\circ} 1 / 2001$, de 3 de janeiro - Ratificação da Convenção sobre os Direitos do Homem e da Biomedicina (Convenção de Oviedo), aberta à assinatura dos Estados Membros em Oviedo, em 4 de abril de 1997. Diário da República. I Série-A;(2).

15. Wong JG, Clare CH, Holland AJ, Watson PC, Gunn M. The capacity of people with 'mental disability' to make a health care decision. Psychol Med. 2000;30(2):295-306.

16. Regulamento n 14/2009, de 11 de janeiro - Código Deontológico da Ordem dos Médicos. Diário da República. II Série;(8).

\section{CONFLITO DE INTERESSES}

Os autores declaram não ter conflitos de interesses.

\section{ENDEREÇO PARA CORRESPONDÊNCIA}

Ricardo Veríssimo

USF Jardim dos Plátanos, ACeS Lisboa Ocidental e Oeiras, ARS Lisboa e Vale do Tejo

E-mail: ricardoverimartins@gmail.com

Recebido em 03-11-2016

Aceite para publicação em 17-16-2017 


\section{ABSTRACT}

\section{DOWN SYNDROME, SEXUALITY AND ETHICAL CONFLICTS: A CASE REPORT}

Introduction: Down syndrome is the most common genetic cause of intellectual disability. Although sexual desire is present, irrespective of the degree of impairment, many families play an overprotective role, treating affected individuals as children and as asexual persons. This may create gaps in their sexual education, increasing their vulnerability to assault and to risk behaviours. This report stresses the importance of sexual education for individuals with intellectual disability and draws attention to ethical matters, which may emerge in this context.

Case description: A 22 year-old woman with the Down syndrome and no other significant past medical history came alone to a family planning appointment after starting a new relationship. She had already had sexual intercourse, although not with her current boyfriend. She was not aware of contraceptive methods, stating that, when it was used in her sexual contacts, it was on the initiative of her partners. She had consented to all sexual contacts but stated that she had felt mistreated once. After the presentation of several contraceptive options, she showed interest in subcutaneous implants. She was informed about the importance of preventing sexually transmitted diseases and about the correct use of condoms. A cervical cytology smear was performed. Since it was difficult to assess the capacity of this young woman to give informed consent, her mother was contacted. She stated that consent should be given by the patient, but was willing to help in informing her daughter about her options. Nothing was revealed to the mother about her daughter's sexual life. Following a negative pregnancy test, a subcutaneous device was implanted. The need for correct use of condoms was repeated. Three months later, she returned for a followup family planning appointment, including a repeat evaluation of her status and further counselling on sexual and reproductive health.

Comment: The health care team faced two challenging ethical questions in this case. Does intellectual disability render this woman incapable of giving informed consent? Could confidentiality be waived to allow her mother to increase her awareness of the need for contraception and to give informed consent? Health care professionals can empower parents to promote sexual health in individuals with intellectual disability including Down syndrome. The family doctor has a role to play in this effort.

Key words: Down syndrome; Intellectual disability; Sexuality; Ethics; General practitioner. 